\title{
Separation of Fine Particles from Gas in Paint- Spraying Booths
}

\author{
Rustem Ya. Bikkulov ${ }^{1}$, Andrey V. Dmitriev ${ }^{1}$, Vadim E. Zinurov ${ }^{1}$, and Guzel R. \\ Badretdinova ${ }^{1, *}$ \\ ${ }^{1}$ Kazan State Power Engineering University, 420066, Kazan, Krasnoselskaya str., 51, Russia
}

\begin{abstract}
Nowadays, at production facilities with paint-spraying booths that use paint and varnish materials to cover the surfaces of product, the problem of gas flow contamination with finely dispersed solid particles of dust and rubbish, which negatively affect the quality of products, is increasingly being raised. In order to minimize the content of solid particles in the gas flow, coarse and fine filters are installed in the paintspraying booths, which prevent dust particles from entering the surface of products. However, the existing purification devices have a number of disadvantages that affect the efficiency of collecting finely dispersed particles from the gas flow with a size of 0.5-5 microns. The authors of article developed a square separator to increase the efficiency of collecting finely dispersed particles from gas flows in the paint-spraying booths. The installation of proposed separation device in the paint-spraying booths affects not only the quality of collecting solid particles, but also increases the service life of fine and coarse filters In the course of numerical studies, the results of impact of structural and technological parameters, namely, the impact of inlet rate and scale of separation device on the efficiency of collecting solid particles from the gas flow, were obtained.
\end{abstract}

\section{Introduction}

The problem of low efficiency of collecting finely dispersed solid particles in the paintspraying industrial booths is gaining large scale, entailing significant energy and economic costs. Paint-spraying booths are special equipment, designed to perform paint and varnish works. Absolutely all paint-spraying booths are fully automated and sealed, as well as equipped with drying devices. Therefore, they are used not only for painting, but also for drying painted products. Often, paint-spraying booths are used for painting car bodies and its parts, as well as for furniture products (doors, facades), wood products of various treatment, etc. Usually, for the formation of glossy coatings, suspension paints with a particle diameter of 0.5 to 5 microns are used [1]. Therefore, the use of efficient equipment allows you to avoid defects that appear due to the faulty sealing of room, thereby preventing dust particles from entering it.

The process of painting products in the paint-spraying booths is carried out as follows: during the painting process, air, entering the booth from the outside, passes through the

\footnotetext{
*Corresponding author: nice.badretdinova@mail.ru
} 
filters, is heated to the required temperature, then fed to the ceiling part of booth and filtered again. Due to the uniform distribution of air, the products are fully painted. A filter is installed in the floor of booth, through which air, contaminated with solid particles, passes, and the cycle starts again. Upon completion of painting process, the booth is cleaned of paint and vapors, and the equipment goes to the drying stage. At this stage, heated air circulates inside the booth, which is constantly updated. Then, paint-spraying booth goes to the cooling stage. As production output, there is an item with a paint coating that meets the modern standards of paint quality. However, during manufacturing of paint products, the quality of paint is significantly affected by the filtration efficiency of paintspraying booth. When using paint and varnish materials at manufacturing plants, filters solve a number of important tasks, such as obtaining high-quality products, ensuring sanitary and hygienic working conditions for personnel, and reducing harmful emissions into the environment. Directly in the paint-spraying booths, filters are used both for prepurification of incoming air, as well as for reduction of solid dust particles and debris in the air, which are removed by the ventilation hood [2-4]. Air purification in the paint-spraying booths is carried out in two stages: first, pre-filtration by means of floor filters of coarse purification, then - ceiling filters of fine purification. At the preliminary stage, coarse filters collect large particles, and fine filters free the heated air from smaller dust particles $[5,6]$.

Thus, the appearance and durability of products depend on the efficiency of collecting solid particles by filters in the paint-spraying booths. However, the significant disadvantages of such filters are the following: low service life, high cost and complexity of their disposal after contamination. The recommended service life of floor filters of coarse purification is 70-120 hours of operation, and of ceiling filters of fine purification is 10001200 hours. Thus, there is a need for frequent replacement of filter material, which requires significant economic costs. In order to solve this problem, various separation devices for collecting small solid particles of different diameters have been proposed [7-13]. Therefore, the development of new devices to improve the efficiency of collecting finely dispersed particles in paint-spraying booths is currently an urgent task.

\section{Description of developed square separation device}

The authors developed a design of square separator, shown in Figure 1, which is proposed to be used in paint-spraying booths for purifying gas flow from finely dispersed particles of 0.5 to 5 microns in size, installing it after the coarse filters, or replacing them as the first stage of purification. This device shall be installed before the fine filters, which will significantly increase service life of them. The separator is a square-shaped casing, which includes separation elements, consisting of square section pipes with round holes on the side faces, and the holes, adjacent to the corners, are 2 times smaller than the holes located at some distance from them, and the space for sediment deposition. In this case, the separation elements of structure are closed on the one side, and open on the other side. The advantage of this device is simplicity of design, low energy consumption, easy removal of the sediment, as well as full restoration of its operability. 


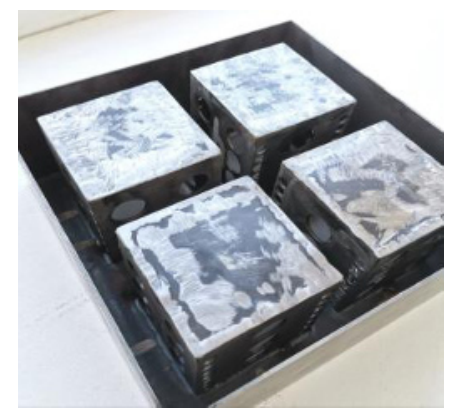

Fig. 1. Square separator for collecting finely dispersed particles from the gas flow.

The process of collecting finely dispersed particles occurs due to the formation of vortex structure inside the device. When passing through the holes, located on the separation elements of device, the gas flow begins to swirl, forming a certain number of vortices over the entire area. According to the condition of equal flow, 4 vortices are formed on the side of each outlet, and the inlet area is equal to the outlet area, i.e. $F_{\text {in }}=F_{\text {out }}$. However, in the center of four square section pipes, a vortex is created that is slightly larger than the others. The peculiarity of developed design is the location of holes, i.e. quantity of them and diameter on the side faces of pipes. Two holes with a diameter of $20 \mathrm{~mm}$ on the side face of one pipe are placed opposite three holes of other pipe with dimensions of 20 $\mathrm{mm}$ and $8 \mathrm{~mm}$, respectively, in such a way that such an arrangement provides twisting of vortices on both sides of side faces of separation elements. Similar arrangement of outlet holes is found on the remaining side faces of square pipes. Due to this arrangement of holes in the device, a stable vortex structure is created that allows to increase the efficiency of collecting finely dispersed particles from gas flows in the paint-spraying booths. The settling of small solid particles down occurs in the "dead" zones of the separator, i.e. the sediment is formed between the vortices and the walls of device. Therefore, during normal operation, the hydraulic resistance practically does not change. However, when the sediment layer is close to the limit value, the resistance begins to increase, as the space, in which the vortex formation occurs, decreases. A device, similar in principle of operation, was installed at the facility of "KAMATEK", which produces products with paint coatings.

Numerical simulations were performed by means of ANSYS Fluent software package, designed for solving problems of fluid mechanics, using the finite element method in the form of unstructured grid technology, which allows you to get an accurate solution for areas with large flow gradients. Transition SST, one of the latest modifications of Menter's SST models, was used as a turbulence model, in which two additional transport equations are introduced; one is for the intermittency of turbulence, and the second one is for the criterion of transition start in thickness units of momentum loss of the Reynolds numbers [14-21]. The number of cells when creating the grid was approximately 785,000.

In the course of numerical studies, a three-dimensional model of square separator was designed, with the following geometric parameters: the diameter of holes is 8 and $20 \mathrm{~mm}$, the height, width and length of square pipes are $80 \mathrm{~mm}$, the distance between the separation elements is $20 \mathrm{~mm}$ (Fig.2). 


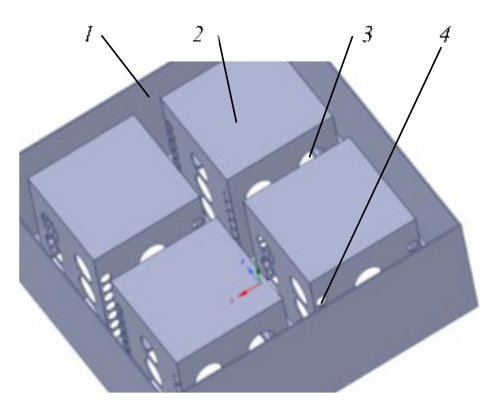

Fig. 2. Three-dimensional model of square separation device: 1 - casing, 2 - separation elements, 3, 4- holes.

During the numerical simulation, the rate range from 1 to $7 \mathrm{~m} / \mathrm{s}$ was set for the solver settings at the inlet to the separation device. The scale of structure was also changed in the ratios 1:1, 1:2, 2:1 accordingly. At the outlet 2, pressure equal to atmospheric one i.e. $101325 \mathrm{~Pa}$ was set, and the air density $\rho$ was taken as equal to $1,2 \mathrm{~kg} / \mathrm{m}^{3}$.

In the course of research, the efficiency of collecting finely dispersed particles from the gas flow in a square separation device was determined by the following formula:

$$
E=1-\frac{n_{\text {out }}}{n_{\text {in }}}
$$

where $n_{i n}$ - the number of particles in the gas flow, entering the device; $n_{\text {out }}-$ the number of particles, collected by the device from the gas flow.

The pressure loss $\Delta p$ in the square separation device was calculated as follows:

$$
\Delta p=p_{1}-p_{2},
$$

where $p_{1}$ - pressure at the inlet 1 of separation device, $\mathrm{Pa} ; p_{2}$ - pressure at the outlet 2 of separation device.

\section{Research results and description of them}

The results of research showed that the efficiency of collecting finely dispersed solid particles from the gas flow in a square separator is affected by the change in the inlet rate and the geometric parameters of device, namely, the set scale. When changing these parameters, it is possible to establish a certain vortex structure that positively affects the efficiency of collecting solid particles by the separator being developed. Stable vortex formation increases the efficiency of collecting with minimal pressure losses in the separation device.

In the course of numerical simulations, an impact of inlet rate on the efficiency of collecting finely dispersed particles in a square separator was studied. For this purpose, the gas flow rate equal to $1,3,5$ and $7 \mathrm{~m} / \mathrm{s}$ was set at the inlet of device, respectively. It was found that for the particles smaller than 3 microns, an increase in the rate from 1 to $7 \mathrm{~m} / \mathrm{s}$ leads to a slight decrease in the collecting efficiency. However, it is worth noting that an increase in the particle diameter within the range from 0.5 up to 5 microns has little impact on the collecting efficiency, which increases from $40-43 \%$ (Fig.3). Since preliminary tests in the paint-spraying booths of KAMATEK LLC show that the particles stick, and do not bounce, the condition for the particles to stick to the walls of device was set. 


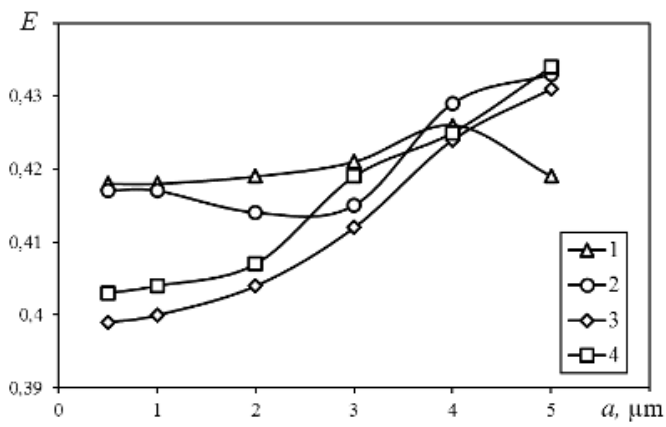

Fig. 3. Dependency of efficiency of collecting finely dispersed particles in the separation device on their diameter within the range of $0.5-5$ microns at the following gas flow rates, $\mathrm{m} / \mathrm{s}: 1-1 ; 2-3$; $3-5 ; 4-7$.

As a result of numerical studies of impact of changing in the square separator scale on the efficiency of collecting finely dispersed particles from the gas flow, when an inlet rate is equal to $5 \mathrm{~m} / \mathrm{s}$, it is observed that a decrease in the geometric dimensions of device leads to the efficiency increase. Thus, for the particles smaller than 2 microns, the efficiency increases by $2 \%$, and for the particles larger than 5 microns, the efficiency increases from 42 to $48 \%$ (Fig. 4). The maximum collecting efficiency is observed at a scale of 1:2 for the entire particle range from 0.5 to 5 microns.

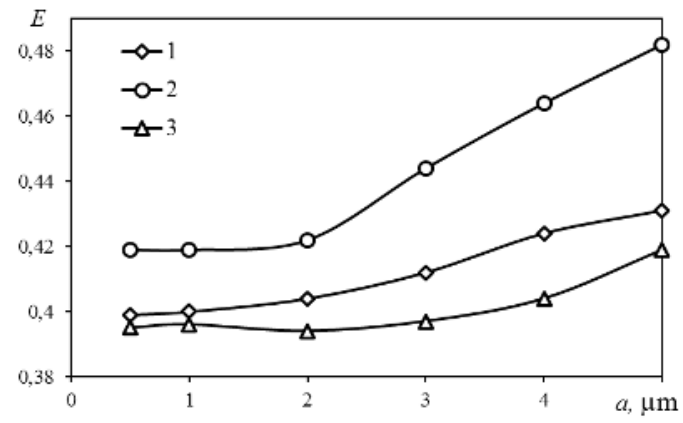

Fig. 4. Dependency of efficiency of collecting finely dispersed particles when $W=5 \mathrm{~m} / \mathrm{s}$ on the scale of separation device: $1-1: 1,2-1: 2,3-2: 1$.

For the studied size range of apparatus and particles, and the rates of dusty gas flow, when the Stokes numbers are within range from 0.00084 to 0.84 , the efficiency of collecting finely dispersed particles increases from 42 to $48 \%$ (Fig. 5). At the same time, this dependency within this range of the Stokes numbers is almost linear. The Stokes number for the obtained dependency was determined by the following formula:

$$
\mathrm{Stk}=\frac{\rho a^{2} w_{v}}{\mu d_{v}},
$$

where $\rho$-particle density, $\mathrm{kg} / \mathrm{m}^{3} ; a$-particle diameter, $\mathrm{m} ; w_{v}$ - gas rate in holes, $\mathrm{m} / \mathrm{s} ; \mu$-dynamic gas viscosity, Pa.s; $d_{v}$ - distance between separation elements, $\mathrm{m}$. 


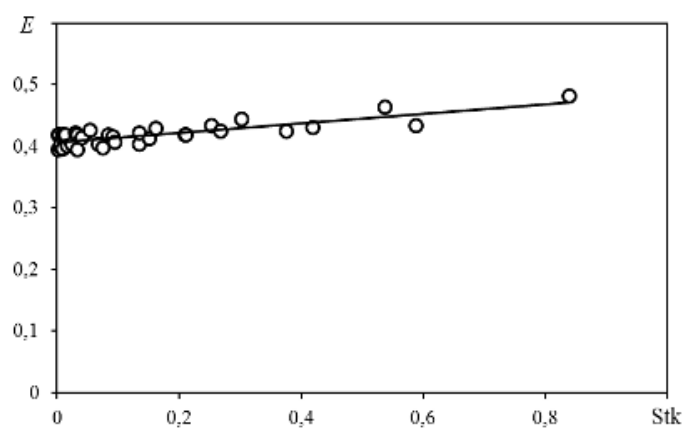

Fig. 5. Dependency of change in the efficiency of collecting finely dispersed particles when the Stokes numbers are equal to $0.00084-0.84$.

The pressure loss in the square separation device is not more than $60 \mathrm{~Pa}$ when the inlet gas flow rate is within the range from 1 to $7 \mathrm{~m} / \mathrm{s}$ and the diameter of square sectional pipe holes is $8 \mathrm{~mm}$ and $20 \mathrm{~mm}$. When the inlet gas flow rate is equal to $1,3,5$, and $7 \mathrm{~m} / \mathrm{s}$, then the pressure loss is equal to $2.2,11.4,29.7$, and $57.3 \mathrm{~Pa}$, respectively (Fig.6). Thus, the pressure loss in the square separator has low values, which is due to the design simplicity. The exponent, when determining the hydraulic resistance, is less than 2, and this indicates the availability of areas where the inside movement has a flow regime close to laminar.

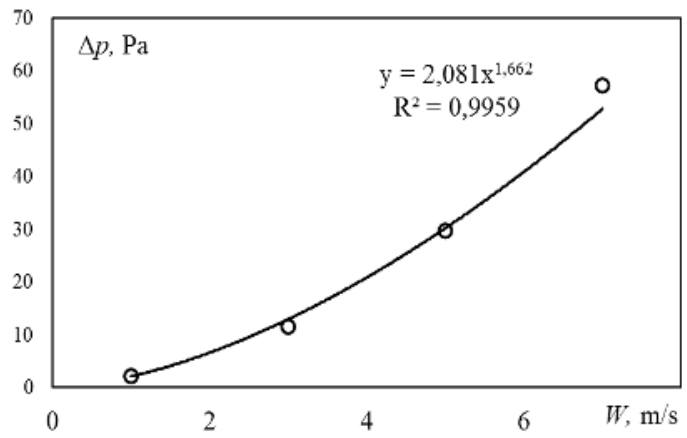

Fig. 6. Dependency of pressure loss $\Delta p$ in the separation device on the gas flow rate within the range of $W=1-7 \mathrm{~m} / \mathrm{s}$.

\section{Conclusion}

At the specified gas inlet rates within the range from 1 to $7 \mathrm{~m} / \mathrm{s}$ for the particles smaller than 3 microns, the collecting efficiency decreases, but the particle size in this case practically does not affect its value. This scientific paper shows a developed square separator for purifying gas flow from finely dispersed particles with sizes from 0.5 to 5 microns in the paint-spraying booths. The results obtained by numerical study demonstrate that the geometric parameters of structure and the inlet gas rate significantly affect the efficiency of collecting finely dispersed particles from the dusty gas in the paint-spraying booths. The efficiency of collecting solid particles at different scales of square separator's design i.e. 1:1, 1:2 and 2:1, respectively, increases with a decrease in the geometric dimensions of device. Thus, the maximum value of collecting efficiency is observed at a scale of 1:2. The pressure loss in this device is not more than $60 \mathrm{~Pa}$, which is due to the formation of stable vortex flow structure in the space between the separation elements. The 
resulting low-pressure losses in the developed square separator have a positive effect on the economic costs of production.

Thus, if the geometric parameters of structure and the inlet rate are chosen correctly, it is possible to create a stable vortex flow structure in the space between the separation elements, which contributes to the effective collecting of finely dispersed particles of $0.5-$ 5 microns in size from the dusty gas flow. The installation of proposed square separator in the paint-spraying booths can solve the problem of deposition of solid paint particles on the surface of product with high efficiency, which leads to its unsuitability, as well as increase the operational life of existing equipment.

The research was conducted with funding from the RF President's grant project No. MK2710.2021.4.

\section{References}

1. Corrosion and corrosion protection. Paint and varnish protective coatings: [website]. URL: www.tehnoinfa.ru/korroziya/107.html

2. Filters for dry-type paint chambers: [website]. URL: biteh.ru/biblioteka/filtry_pokrasochnyh_kamer/

3. A. Sabirova, S. Wang, G. Falca, P.Y. Hong, S.P. Nunes, Flexible isoporous air filters for high-efficiency particle capture, Polymer, v. 213, pp. 123278 (2021)

4. O.V. Soloveva, I.R. Ilyasov, R.R. Khusainov, R.R. Yafizov, N.D. Yakimov, Investigation of the influence of the internal structure of a highly porous mesh filter on the efficiency of particle deposition, Bulletin of the Kazan State Power Engineering University, v. 4(40) (2018)

5. E. Tian, J. Mo, Z. Long, H. Luo, Y. Zhang, Experimental study of a compact electrostatically assisted air coarse filter for efficient particle removal: Synergistic particle charging and filter polarizing, Building and Environment, v. 135, pp. 153-161 (2018)

6. S.B. Lee, H.J. Cho, Y.M. Ha, S.J. Kim, B.J. Chung, W.K. Son, K.S. Kang, Y.C. Jung, K. Park, J.S. Lee, Enhancing the durability of filtration the ultrafine aerosol by electrospun polymer filter containing quaternary ammonium moiety, Polymer, v. 121, pp. 211-216 (2017)

7. A. Podgorski, A. Bałazy, L Gradon, Application of nanofibers to improve the filtration efficiency of the most penetrating aerosol particles in fibrous filters, Chemical Engineering Science, v. 61(20), pp. 6804-6815 (2006)

8. B. Brouwers, Rotational particle separator: A new method for separating fine particles and mists from gases, Chemical Engineering \& Technology: Industrial Chemistry-Plant Equipment-Process Engineering-Biotechnology, v. 19(1), pp. 1-10 (1996)

9. P. Zhang, G. Chen, J. Duan, W. Wang, Experimental evaluation of separation performance of fine particles of circulatory circumfluent cyclone separator system, Separation and Purification Technology, v. 210, pp. 231-235 (2019)

10. J. Jiao, Y. Zheng, G. Sun, Numerical simulation of fine particle separation in a rotational tube separator, China Particuology, v. 3(4), pp. 219-223 (2005)

11. P. Liu, Y. Ren, M. Feng, D. Wang, D. Hu, A performance analysis of inverse two-stage dynamic cyclone separator. Powder Technology, v. 351, pp. 28-37 (2019) 
12. S. Venkatesh, S.P. Sivapirakasam, M. Sakthivel, S. Ganeshkumar, M.M. Prabhu, M. Naveenkumar, Experimental and numerical investigation in the series arrangement square cyclone separator, Powder Technology, v. 383, pp. 93-103 (2021)

13. J.G.M. Kuerten, B.P.M. van Esch, H.P. van Kemenade, J.J.H. Brouwers, The effect of turbulence on the efficiency of the rotational phase separator, International journal of heat and fluid flow, v. 28(4), pp. 630-637 (2007)

14. S.G. Gendler, I.R. Fazylov, Methods of regulation air temperature in the Russian oil mains, Topical issues of Rational Use of Natural Resources. Taylor \& Francis Group, v. 1, pp. 16-21 (2019)

15. R.B. Langtry, F.R. Menter, Correlation-Based Transition Modeling for Unstructured Parallelized Computational Fluid Dynamics Codes, AIAA Journal, v. 47(12), pp. 2894 - 2906 (2009)

16. P.A. Baranov, S.V. Guvernyuk, M.A. Zubin, S.A. Isaev, A.E. Usachov, Application of various models of turbulence for calculation of incompressible internal flows, TsAGI Science Journal, v. 48(1) (2017)

17. V.E. Zinurov, O.S. Dmitrieva, O.S. Popkova, Collecting finely-dispersed particles from the gas flow in a centrifugial separator with coaxially arranged pipes, Matec Web Conf. v. 315, pp. 03003 (2020)

18. V.E. Zinurov, A.V. Dmitriev, G.R. Badretdinova, R.Ya. Bikkulov, I.N. Madyshev, The gas flow dynamics in a separator with coaxially arranged pipes, MATEC Web of Conferences, v. 329, pp. 03035 (2020)

19. V.E. Zinurov, A.V. Dmitriev, M.A. Ruzanova, O.S. Dmitrieva, Classification of bulk material from the gas flow in a device with coaxially arranged pipes, MATEC Web of Conferences, v. 193, pp. 01056 (2020)

20. V.E. Zinurov, N.Z. Dubkova, O.S. Popkova, O.S. Dmitrieva, Efficiency of different separation elements for removal of fine particles from gas, Journal of Physics: Conference Series, v. 1745, pp. 012090 (2020)

21. A.V. Dmitriev, V.E. Zinurov, O.S. Dmitrieva, Collecting of finely dispersed particles by means of a separator with the arc-shaped elements, E3S Web of Conferences. EDP Sciences, v. 126, pp. 00007 (2019) 